
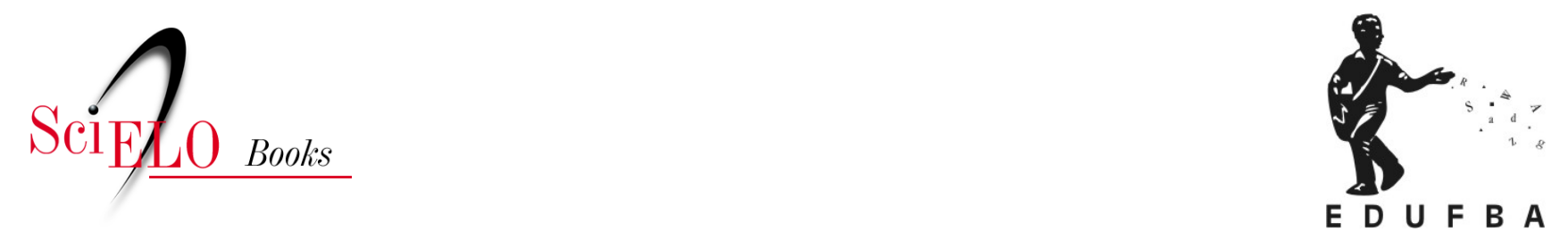

\title{
A política de expansão da Capoeira Regional
}

\author{
Hellio Campos
}

\section{SciELO Books / SciELO Livros / SciELO Libros}

CAMPOS, H. A política de expansão da Capoeira Regional. In: Capoeira regional: a escola de Mestre Bimba [online]. Salvador: EDUFBA, pp. 262-268. ISBN 978-85-232-1727-3. Available from: doi: $10.7476 / 9788523217273.0021$. Also available in ePUB from: http://books.scielo.org/id/p65hq/epub/campos-9788523217273.epub.

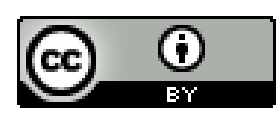

All the contents of this work, except where otherwise noted, is licensed under a Creative Commons Attribution 4.0 International license.

Todo o conteúdo deste trabalho, exceto quando houver ressalva, é publicado sob a licença Creative Commons Atribição 4.0.

Todo el contenido de esta obra, excepto donde se indique lo contrario, está bajo licencia de la licencia Creative Commons Reconocimento 4.0. 


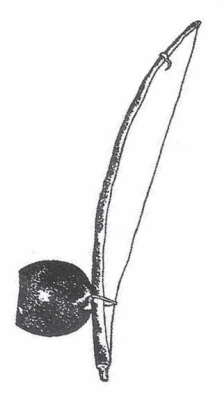

A política de expansão da Capoeira Regional

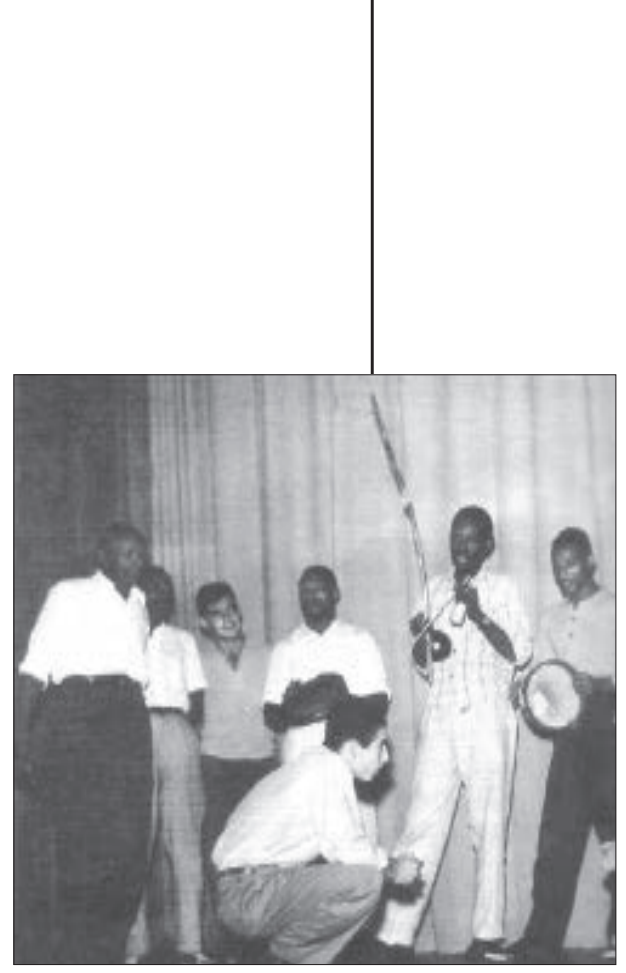




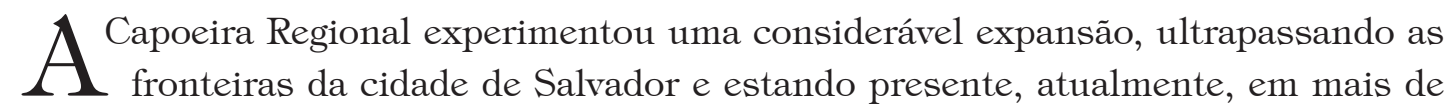
setenta e dois países. Certamente, o grau de comprometimento dos alunos de Mestre Bimba contribuiu para isso, para a expansão deste modo de jogar capoeira, mas também para a edificação deste estilo, também conhecido como Luta Regional Baiana.

Comentando a origem e o desenvolvimento da Capoeira Regional, Decanio afirma que a "Luta Regional Baiana está diretamente ligada a alguns fatos históricos da década de 1930", especialmente a chegada a Salvador de Cisnando Lima. Logo que conheceu Mestre Bimba, este jovem líder estudantil, forte, inteligente e esportista praticante de halterofilismo e amante das artes marciais, se enfeitiçou pela Capoeira Regional.

O cearense e estudante de medicina Cisnando foi o primeiro aluno branco de Bimba pertencente à classe social dominante, em Salvador. Com seu espírito de liderança, poeta, sonhador e idealista por natureza, logo persuadiu Mestre Bimba a enriquecer o potencial da Capoeira Regional.

Mestre Pavão ${ }^{1}$, falando da genialidade de Bimba, disse ele era uma pessoa que aprendeu com o mundo e, assim, conseguiu influenciar o mundo pela proximidade da cultura, pois o cultural está presente no mundo inteiro. Chama a atenção ainda para o fato de que a genialidade do mestre está principalmente na sua capacidade de aprender com seus alunos. "Diferente do que muitos pensam, que Bimba criou a Regional na década de trinta e acabou, ele, enquanto esteve vivo, não parou de criar a Capoeira Regional"

Este comentário de Pavão me remete a lembranças interessantes que, muito a propósito, vêm confirmar o aprendizado recíproco existente entre Mestre Bimba e seus alunos. Lembro-me que frequentava assiduamente as aulas das 14 horas, nas segundas, quartas e sextas-feiras, lá na academia da Rua das Laranjeiras, Maciel de Cima, e já com alguns conhecimentos de Educação Física comecei, a pedido dos colegas de turma, a puxar o aquecimento, alongamentos, corridas em volta da sala, jogos vivificantes, apoios e exercícios abdominais. Para minha surpresa, o mestre nunca reclamou de nada, apenas observava e até fazia gracejos na hora dos apoios e abdominais. Foi para mim um belo incentivo!

Acompanhei bem de perto a participação de Medicina e Galo na organização administrativa do grupo de Mestre Bimba. Eles estavam sempre implementando algo novo na academia, buscando não apenas melhorar a organização administrativa, mas, sobretudo, 
expandir a Capoeira Regional através de apresentações em escolas, clubes e principalmente em eventos ligados ao turismo.

Galo, assim comenta esta experiência:

\begin{abstract}
Houve um embate, comigo e Mestre Decanio. Não somente mestre na Capoeira, também mestre na medicina. Nós nos digladiamos no bom sentido por uma conduta organizacional e administrativa que nós queríamos dar um cunho mais moderno aquela administração da Academia. Nós éramos da diretoria e o mestre ficava observando os desentendimentos. Então eu disse que daquele jeito não dava pra ficar, não dava mais e que era melhor ficar Decanio. Helio, não sei se você sabe disso, Mestre Bimba teve lá em casa. Camisa e Itapoan me disseram que nunca tinham visto o mestre, e na casa de ninguém, rapaz, minha mãe chegou e falou para mim que tinha uma pessoa querendo falar comigo, era Mestre Bimba, lamentavelmente eu não bati uma foto e nem podia, foi uma surpresa. Ele foi ao meu encontro para tentar contemporizar a situação vexatória de discordância em que nós estavamos vivendo (sic).
\end{abstract}

Continua contando que em algumas viagens com o mestre chegou a viajar do lado dele, "era uma pessoa que ensinava sem precisar estar em uma roda de capoeira, como continua ensinando a gente até hoje, mesmo à distância".

Para Gato Branco, “[...] os alunos de Mestre Bimba vão ser sempre os eternos alunos de Mestre Bimba e fazendo trabalho de divulgação da capoeira. Hoje não tem mais como a capoeira deixar de ter um lugar de destaque no cenário nacional, no contexto mundial". Ressalta, certificando que "tudo começou com ele (Mestre Bimba); acredito que tenha sido o precursor de tudo e por tudo o que ele fez, por tudo o que ele ensinou, por todo aquele jeito especial dele". Chama a atenção para o fato de que "muitos alunos de Bimba estão por aí hoje fazendo trabalho em cima da capoeira, trabalho sério, trabalho acadêmico" (sic).

Segundo Cafuné:

Veja bem, eu nunca assisti pessoalmente alguém interferir assim tão objetivamente, mas ele era aberto, ele aceitava, muitas vezes os alunos mais antigos chegavam com alguma coisa assim e ele deixava que a gente fizesse, que a gente praticasse, ele não interrompia não. A não ser que fosse alguma coisa que ferisse os princípios do trabalho dele, aí realmente ele não deixaria (sic).

Sobre o comprometimento dos alunos de Bimba, Medicina assim se refere: "Em relação ao potencial cultural e socioeconômico que a Capoeira Regional representa, para o Brasil e para o mundo, tenho a impressão de que é um comprometimento diminuto. Podemos e devemos, todos, nos comprometer muito mais". Fala ainda de suas lembranças, afirmando: "Participei em muitas ocasiões de reuniões com Mestre Bimba, para organizar os shows do seu grupo de apresentações. Naquelas oportunidades, discutíamos sobre as duplas, hora do show, esquete, coreografia do maculelê etc."

Já foi largamente dito neste estudo que a Capoeira Regional não pertence mais à Bahia, pertence ao Brasil e ao mundo, por esse motivo perguntamos: Mestre Bimba tinha uma política de expansão da Capoeira Regional? Três dos entrevistados responderam negativamente, o que justificaram. Decanio disse que Bimba era semi-analfabeto, portanto, não conhecia nada sobre política e que ele era a Capoeira Regional, detinha o poder da capoeira que criou. Sariguê observou que, "se tivesse uma política, ele não aceitaria que os alunos interferissem na Capoeira Regional". Sacy disse que o mestre enclausurava seus alunos, não permitindo que eles se identificassem como capoeiristas, muito menos aconselhava a ensinarem a Capoeira Regional, porém, seus alunos mais destacados, a exemplo 
de Camisa Roxa, Acordeon e outros, insatisfeitos com esse procedimento e mentalidade, deram início a uma nova etapa, apresentando-se em locais abertos. Dessa maneira, Mestre Bimba acordou para a idéia de divulgar a sua Capoeira. A princípio não existia uma política definida de expansão, mas posteriormente, cedendo aos anseios dos seus alunos, passou a desenvolver a política de expansão da Capoeira Regional.

Sariguê conta que foi um dos que divulgou e vem divulgando a Capoeira Regional, em várias oportunidades. Para começar, ministra aulas de Capoeira Regional na escola pública, como professor de Educação Física; fez parte do grupo de apresentações do Mestre Bimba, inclusive fazendo apresentações em Goiânia, para o Presidente Emílio Garrastazu Médici, depois no Iate Clube de Brasília; integrou também o Grupo Folclórico Olodumaré, a convite de Camisa Roxa, também aluno de Bimba, que, antes de pedir o consentimento de seus pais para viajar em turnê pelo Brasil e exterior, foi falar com Mestre Bimba, justamente por ser Sariguê aluno do mestre e não ter a maioridade. No grupo Olodumaré, Sariguê pôde constatar que a maioria dos integrantes pertencia à academia de Mestre Bimba. Conta ainda que, na sua passagem pela Coréia, teve a oportunidade de mostrar a capoeira, quando realizava o curso avançado de Tae-kwon-dô.

Os outros dois entrevistados responderam afirmativamente. Mestre Fred assim se reporta ao assunto:

Não sei se a gente pode entender, pelo conceito moderno de política de expansão. Acredito que ele tinha em mente planos para a expansão da Regional. Acredito até que dentro da própria Regional, embutida, estivesse uma política de expansão para a capoeira. Ela parece evidente nesta frase que a ele é atribuída: "Quero ver meus alunos ensinando capoeira no mundo inteiro". A criação de núcleos de ensino-academias, as viagens culturais do mestre, a disponibilidade do mesmo para conversar com intelectuais, jornalistas; seu desejo de penetrar e conquistar novos espaços para a capoeira, atrair novos praticantes, estabelecer novos ares para a capoeira, parece-me revelador de uma política de expansão. Bimba é um dos responsáveis para que a capoeira ultrapasse as barreiras de classe, raça, língua, condição social e possa se estabelecer como uma contribuição dos afro-brasileiros para melhorar os contatos entre os povos (sic).

Para Mestre Cafuné,

Acredito que sim, não como uma política consciente de expansão, ele adquiria alunos através de informações de pessoas que já frequentavam sua academia ou de pessoas que liam suas entrevistas nos jornais, era um meio de propagar seu trabalho e adquirir um número maior de alunos dentro de suas possibilidades de ensiná-los. Era expansão de seu trabalho e não da capoeira regional espalhada pelo mundo como hoje. Porém ele dizia que quando ele morresse haveria um mestre em cada esquina ( $\mathrm{sic}$ ).

É evidente a discordância inicial entres os entrevistados. Os três primeiros afirmam não existir uma política de expansão idealizada por Mestre Bimba, que o mesmo, por ser quase analfabeto, desconhecia essas particularidades. Os outros dois mestres parecem entender a questão, em maior profundidade, trazendo à tona a idéia ampliada de política, como "política inconsciente" e como "conceito moderno de política", mas todos concordam com a influência decisiva dos alunos no processo de expansão da Capoeira Regional.

Porém, diante da presença da Capoeira Regional nos mais longínquos rincões do Brasil e do mundo, perguntamos: a quem atribuir esta expansão? 
Todos os entrevistados responderam que essa conquista deve-se à Capoeira Regional. Mestre Sacy ressalta que a capoeira teve dois períodos distintos, antes e depois de Bimba, criador da Regional. No primeiro período, a capoeira era praticada nas periferias da cidade e por pessoas social e economicamente menos favorecidas, as quais, sem serem marginais, eram "descredenciadas" socialmente. A segunda fase na academia de Mestre Bimba, onde Bimba facilitou o acesso de uma nova camada social, composta na sua maioria por estudantes e profissionais liberais, daí a capoeira transpor as fronteiras do Estado da Bahia. Sariguê diz que Mestre Bimba monopolizou a capoeira, devido ao novo estilo criado por ele, e que se sobressaía entre outros capoeiristas da época.

Cafuné assim se refere:

Bimba tirou a capoeira da marginalização e a introduziu no seio da sociedade entre 1918 a 1928 e até à sua morte em 1974, criando condições para a sua expansão no mundo. Pouco antes de Mestre Bimba morrer, alguns alunos dele já haviam subido aos palcos, participando de grupos de shows folclóricos ou culturais. Estes alunos, ao adquirirem fama e algum dinheiro, principalmente no exterior, promoveram a capoeira, e como a maioria era oriunda da Regional e até os que não eram legitimamente regional se intitulavam assim, logo foi a regional responsável por esta expansão.

Para Fred:

Muita gente e muitos fatores estão envolvidos neste processo, porém, diz ser Mestre Bimba um importante elo, e ressalta que ele ganha em notoriedade no momento em que se reconhecem outros mestres, outros capoeiristas e outras pessoas que são capoeiristas que contribuem de forma resoluta para isso. Mesmo no momento em que Bimba atuou efetivamente para que a expansão da Capoeira acontecesse, outros personagens também foram deveras importantes, como Édílson? Carneiro, que também tentava por outras vias, legitimar e firmar a Capoeira (sic).

Queijadinha d'Angola chama a atenção dizendo que a Capoeira Regional contribuiu de maneira incisiva, especialmente referindo-se a sua "inclusão e aceitação na esfera do esporte de rendimento, do esporte institucionalizado, da educação física e do desenvolvimento do processo de sua escolarização". Ressalta também que a "Capoeira Angola participa desse processo na medida em que se mantém próxima ao sentido de manifestação cultural da classe trabalhadora, pobre, negra e mestiça". Levanta a questão da resistência cultural e de uma manifestação corporal que foge dos padrões determinados pala sociedade capitalista. Diz tornar-se uma importante "referência da cultura afro-brasileira, afro-baiana, principalmente com um jeito de ser-estar no mundo" (sic).

Um outro questionamento indaga se Mestre Bimba exercia o poder da capoeira na Bahia.

Os entrevistados discordam quanto a Bimba ser o todo poderoso da capoeira na Bahia. Para Mestre Decanio, Mestre Bimba era a capoeira da Bahia e era a figura da Capoeira Regional, tudo era ele, tinha que ser do jeito dele. Mestre Fred discorda e acha que Bimba foi muito contestado, em determinada época, e chegou a se isolar, porém destaca que, no período dos anos 1930 a 1970, ele exerceu uma hegemonia. "Era o mais famoso, o mais solicitado, o que tinha mais alunos". "Na medida em que surgiram novas demandas e ele não pode acompanhar, outros mestres, sem a mesma tradição dele, terminaram por quebrar a bipolarização que existia da capoeira em torno de Bimba e Pastinha, em função da demanda oriunda da sociedade". 
Cafuné acha que Bimba exercia o poder na capoeira da Bahia e afirma o seguinte:

Mestre Bimba praticava e ensinava a Luta Regional Baiana que era uma arte de defesa pessoal que incluía a capoeira como o seu principal item. Era uma capoeira viril, dura, de muita técnica e ele exigia muito respeito de seus praticantes e este respeito ia além de sua academia, ganhava as ruas, sendo seus alunos respeitados, temidos ou odiados, fazendo com que Mestre Bimba exercesse um largo poder na capoeira da Bahia. No mundo da capoeira ou se adorava Bimba ou o odiava (sic).

Sacy é veemente, dizendo que "sem dúvida alguma, uma liderança" e lembra que muitas pessoas vinham de outros estados brasileiros aprender e buscar o aperfeiçoamento na Capoeira Regional com Mestre Bimba. Cita Gato, do Rio de Janeiro, e Osvaldo, de Goiás, que desenvolveram seus grupos de capoeira, ativos até os dias de hoje.

Queijadinha d'Angola enfatiza que Mestre Bimba não exercia sozinho o poder da capoeiragem baiana. Explicando o seu comportamento político, cita que Bimba era uma das "principais referências da capoeira da Bahia, porém tinha que dividir, mesmo contra a sua vontade, o espaço político, principalmente com os mestres Pastinha, Waldemar da Pero Vaz, Noronha, Cobrinha Verde e Canjiquinha".

Quanto à participação dos alunos de Mestre Bimba na política de expansão da Capoeira Regional, Sacy diz que "foram eles os responsáveis diretos pela expansão da Capoeira, apresentando-se em shows folclóricos em nível internacional e realizando competições, cujas regras foram por eles estabelecidas", mas acrescenta "com ajuda do Mestre".

Mestre Fred afirma ser "verdade que a grande expansão da Regional aconteceu no Brasil, após a morte de Bimba e este serviço foi executado pelos seus alunos".

Cafuné relata:

Que o carisma de Bimba, a maneira como ele os tratava, o respeito que Bimba mantinha por seus alunos fazia que aqueles alunos divulgassem e promovessem a nossa academia. Alunos como Camisa Roxa, Acordeon, Ezequiel, Airton Onça, Itapoan e tantos outros, ao subirem aos palcos para os shows artísticos e ao montarem suas próprias academias e com isto ganhando fama e até algum dinheiro promoveram a atual expansão da Regional (sic).

Sariguê afirma que mesmo os alunos de Mestre Bimba sendo estudantes e exercendo outras profissões, passaram a ensinar a Capoeira Regional e, portanto, foram os grandes responsáveis por essa explosão da capoeira no Brasil e no mundo.

Decanio, no seu livro a "Herança de Mestre Bimba", ressalta a influência dos alunos na concretização da Capoeira Regional e que "Cisnando logo induziu Mestre Bimba a enriquecer o potencial bélico da luta negra, acrescentando movimentos oriundos de outros processos culturais africanos, não fazendo modificação alguma capaz de descaracterizar a capoeira em si ou alterar seus rituais consolidados". Sabe-se que Bimba incorporou elementos próprios da vida acadêmica, como exame de admissão, convite, formatura, paraninfo, madrinha, padrinho, orador, quadro de formatura e curso de especialização, através da convivência com seus alunos universitários.

Mais uma vez Queijadinha d'Angola enfatiza que "não houve uma política de expansão da Capoeira Regional". Quando se refere às estratégias usadas por Bimba para promover a Capoeira Regional, enumera vários intentos, a exemplo das lutas e desafios no ringue, 
apresentações em escolas e universidades, criação do grupo folclórico para shows, criação de uma academia (escola de capoeira), produção de discos, entrevistas na imprensa falada e escrita, permanente contato com órgãos de turismo da Bahia, aproximação com os estudantes universitários e a classe média, branca e letrada, e a manutenção de um clima amistoso de concórdia com os representantes e praticantes da Capoeira Angola.

De posse desses elementos, entendemos não ser suficiente adotarmos uma posição definitiva sobre a política de expansão da Capoeira Regional. No entanto, podemos antecipar que Mestre Bimba tinha um projeto para a sua capoeira, a Luta Regional Baiana. Como disse Cafuné, "tinha, sim, uma política 'inconsciente' de expansão da Capoeira Regional". Por esse motivo, ele afirmava "quero meus alunos ensinando capoeira no mundo inteiro", mas não detinha uma educação suficientemente embasada que o possibilitasse traçar estratégias e objetivos claros, sistematizados, os quais iam acontecendo no seu cotidiano.

A rigor, Mestre Bimba usava a sabedoria para contrabalancear as suas limitações na realização da sua criação, aceitando assim as contribuições advindas dos seus discípulos para a sistematização, consolidação e expansão da Capoeira Regional.

${ }^{1}$ Comunicação pessoal, em março de 2005. 